\title{
Development of a Strategic Planning Model for a Municipal Water Supply Scheme Using System Dynamics
}

\author{
Adelere E. Adeniran1*, Olufemi A. Bamiro² \\ ${ }^{1}$ Civil \& Environmental Engineering Department, University of Lagos, Lagos, Nigeria \\ ${ }^{2}$ Mechanical Engineering Department, University of Ibadan, Ibadan, Nigeria \\ Email: engrea@yahoo.com, femi.bamiro@skannet.com
}

Received 24 August 2015; accepted 12 October 2015; published 15 October 2015

Copyright (C) 2015 by authors and Scientific Research Publishing Inc.

This work is licensed under the Creative Commons Attribution International License (CC BY).

http://creativecommons.org/licenses/by/4.0/

(c) (i) Open Access

\section{Abstract}

This paper reports the development of a system dynamics model for the strategic planning of a municipal water supply scheme. The model is capable of handling the critical variables that impact on the operations of a water supply scheme. The model was developed using the dynamo programming software to handle the process dynamics. Other supporting softwares-Fortran, Clipper 5, and Epiglue are used to handle data input, analysis and presentation of results in a userfriendly environment. The model was validated by applying it to the simulation of the University of Ibadan Water Supply Scheme for which extensive data of operations were collected over a period of ten years. The results obtained were found to be realistic and useful for the planning of plant operations. It is concluded that the model developed is sensitive to variable changes and has the capability of answering various operational "what-if" questions. As a strategic planning tool, the present model generates, for different scenarios, important operational information for the management of the water supply scheme. It is concluded that SD model is a useful tool to assist water managers and policy makers in making decisions and evolving strategic planning for water supply.

\section{Keywords}

Municipal Water Supply, System Dynamics, Strategic Planning, Policy Decisions

\section{Introduction}

The city of Ibadan has been faced with water scarcity since the late 1980s. The scarcity of water in the city af-

${ }^{*}$ Corresponding author.

How to cite this paper: Adeniran, A.E. and Bamiro, O.A. (2015) Development of a Strategic Planning Model for a Municipal Water Supply Scheme Using System Dynamics. Journal of Water Resource and Protection, 7, 1183-1194. 
fected the University of Ibadan (UI) culminating in a fire incident that gutted a female undergraduate hostel. The management and operation of a Water Supply Scheme in an African metropolis is a complex and challenging problem that has cultural dimensions and demands a high level of strategic planning. A tool that can facilitate the performance of these functions is a step in the right direction [1].

The management of the scarce water requires the development and operation of a model that can handle the complex dynamics that is involved [2]. In this paper, a System Dynamic (SD) model is used to capture the dynamics and the structure of the UI water supply system. The developed model was tested as a tool for making strategic planning decisions using simulations to replicate various scenarios. The objective of such a Strategic Planning Model for a Municipal Water Supply Scheme (SPMWSS) was to develop a strategic planning tool that would give the water managers, planners, policy and decision makers, flexibility in assembling and testing water management strategies for the university and similar settlements. A strategy may include structural measures to increase supply capacity as well as managerial options to manage water supply, reduce costs and to allocate water supply to various demand units at varying quantities and time [3].

The simulation system is designed with the appreciation that there are several limitations on the processing and computing abilities of human managers and decision makers. A model for water supply management must necessarily focus attention on the flow of information in a complex water supply management system, and the use of such information in the decision making process. It should also focus attention on the role that simulation can play in gaining insights into current and future water management policies and strategies [4].

Three types of information can be used in the development of a strategic planning model: mental, written and numeric [5] [6]. In the development of the SPMWSS model, the mental information relied on the mental data base of the authors and those of their colleagues in the water unit of the University and it reliably captured the structure and policies governing management of the water supply scheme in UI. On the other hand, written data on water supply problem and modelling strategies abound. Several articles and conferences have tried to focus attention on paradigm shift and the need to apply modelling techniques to strategic planning in the water supply industry. The principles of SD are well suited for modeling and application to water resources and environmental problems [7]-[9]. SD is as an emerging tool with great potentials for improved understanding of environmental systems [10]. Numerical data used in building the model were collected and reviewed. For our problems, these included data from 1991 to 2003 kept by the UI water unit and unpublished reviews from consultants engaged at different times for improvement to the university's water supply.

\section{Concept, Structure and Development of the SPMWSS}

The simulation model was formulated base on System Dynamics theory. System Dynamics, as an aspect of system theory, is a method for understanding the dynamic behavior of complex systems. The governing equations represented by finite difference expressions used for modeling different elements in a system are solved using standard numerical schemes [11]. System Dynamics modelling has attracted considerable attention over the past few decades. In a particular sense, System Dynamics is concerned with the use of models and modelling techniques to analyse complex systems and policy issues with a view of getting the right combination of scenarios to accomplish an efficient strategic planning for the system being modelled [3].

In the SPMWSS model, DYNAMO, FORTRAN, CLIPPER 5 and EPIGLUE programming languages are combined to develop a user-friendly and menu-driven environment to drive the model. The simulation model consists of four major sectors.

The finance module includes details of the capital, operational and maintenance financial analysis. It is further sub-divided into (i) total cost in a 12-month cycle which can be used for budgeting and (ii) production and unit cost analysis which can be used for tariff setting mechanisms. The production module includes the model representation of population, per capita demand and supply and demand management options. The operation and maintenance module captures the pumping operations, availability, spare parts and maintenance schedules. It also includes store and inventory schedules. The distribution module lists the various water uses and demand nodes and their usage potentials. It incorporates the reservoirs and the pumping stations. Each module is a standalone but is interlinked with other module. Each of the modules also represents an aspect of water management from the point of view of sectoral interdependency (Figure 1).

The four modules are then housed in the SPMWSS model as interactive and interdependent components for the strategic planning of a Municipal Water Supply constituting the global system. 


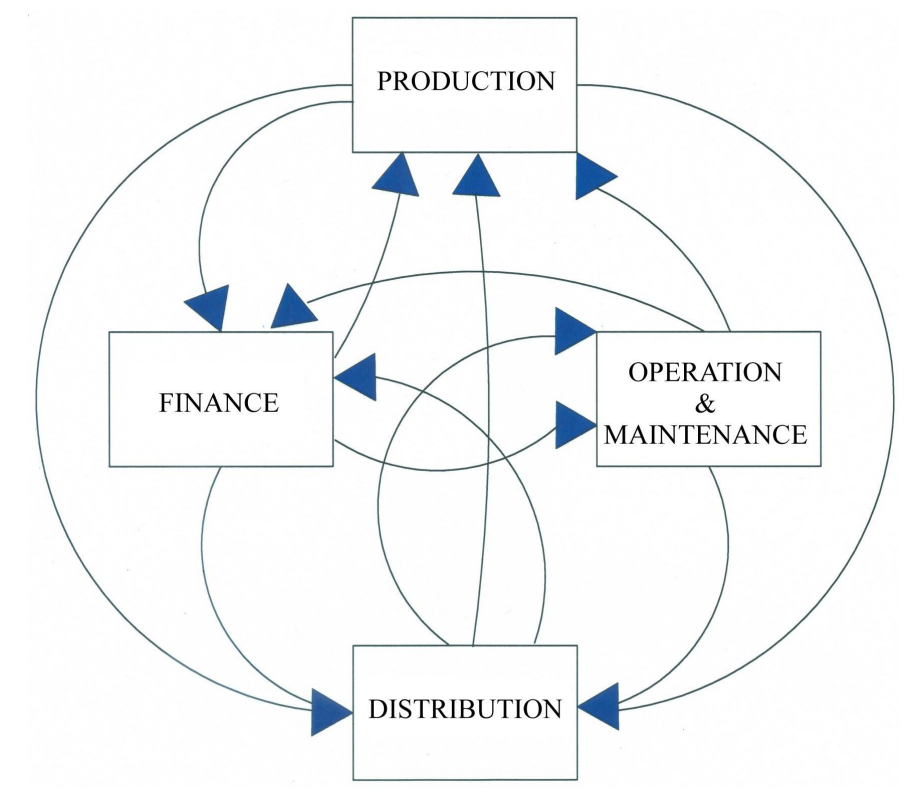

Figure 1. Interconnectivity of the major components of the SPMWSS model. Source: Adeniran (2007).

The concept of the SPMWSS model is as illustrated in Figure 2. The total model is segregated into three stages viz.: (i) Supporting Data Interface, (ii) Main SPMWSS Simulation Model and (iii) Report Generator Systems. The three-stage model concept is based on the identified interdependencies. In the SPMWSS, the DYNAMO language was adopted to model the various components and variables identified. The Equations are based on the mathematical philosophy of System Dynamics, the interconnectivity of the Water Supply System and the Syntax of DYNAMO modelling. The complete DYNAMO program listing (UIWATER.DYN) for the SPMWSS and the exogenous data file (UIWATER.ASC) is presented in [3].

\section{Model Validation}

The SPMWSS model is validated based on the rendition that the model must have the ability to replicate the real life system being modeled under the same parametric conditions. It is the validation of the basic underlying processes of the model (Design Validity). Selected endogenous variables, which are representative of the water supply system's behaviour, which have been collected from 1991 to 2003, are used to validate the model over a 12-month planning horizon each. Comparison of the model output with actual historical data over the same time period provides the required validation.

Figure 3 shows the comparison of the Actual Production for the years 1992 to 2002 under the real life operating conditions as available in the Water Works records as compared with the simulated outputs of the SPMWSS model for the same period. A comparison of simulated versus actual data shows that the variance is less than $5 \%$ and hence considered within reasonable limits.

Figure 4 compares the Actual Monthly production as available in the Water works records with the SPMWSS simulated Production under the same operating conditions for the year 2002. It is concluded from the two examples that the model replicates the system fairly well.

\section{Application of SPMWS: Scenario Investigations}

Since the primary objective in building SPMWSS is the conduct of scenario experiments for strategic planning, considerable thought is given to the types of experimental features that must be built into SPMWSS to ensure effective and efficient scenario simulations can be carried out. The utilization of SPMWSS is oriented toward scenario experiments to production, finance and maintenance situations that will assist Management in short term and long-range and strategic planning of the water supply system. Scenario investigations allow the model users to ask "what-if" questions. The following strategic "what-if" questions were investigated using the model 


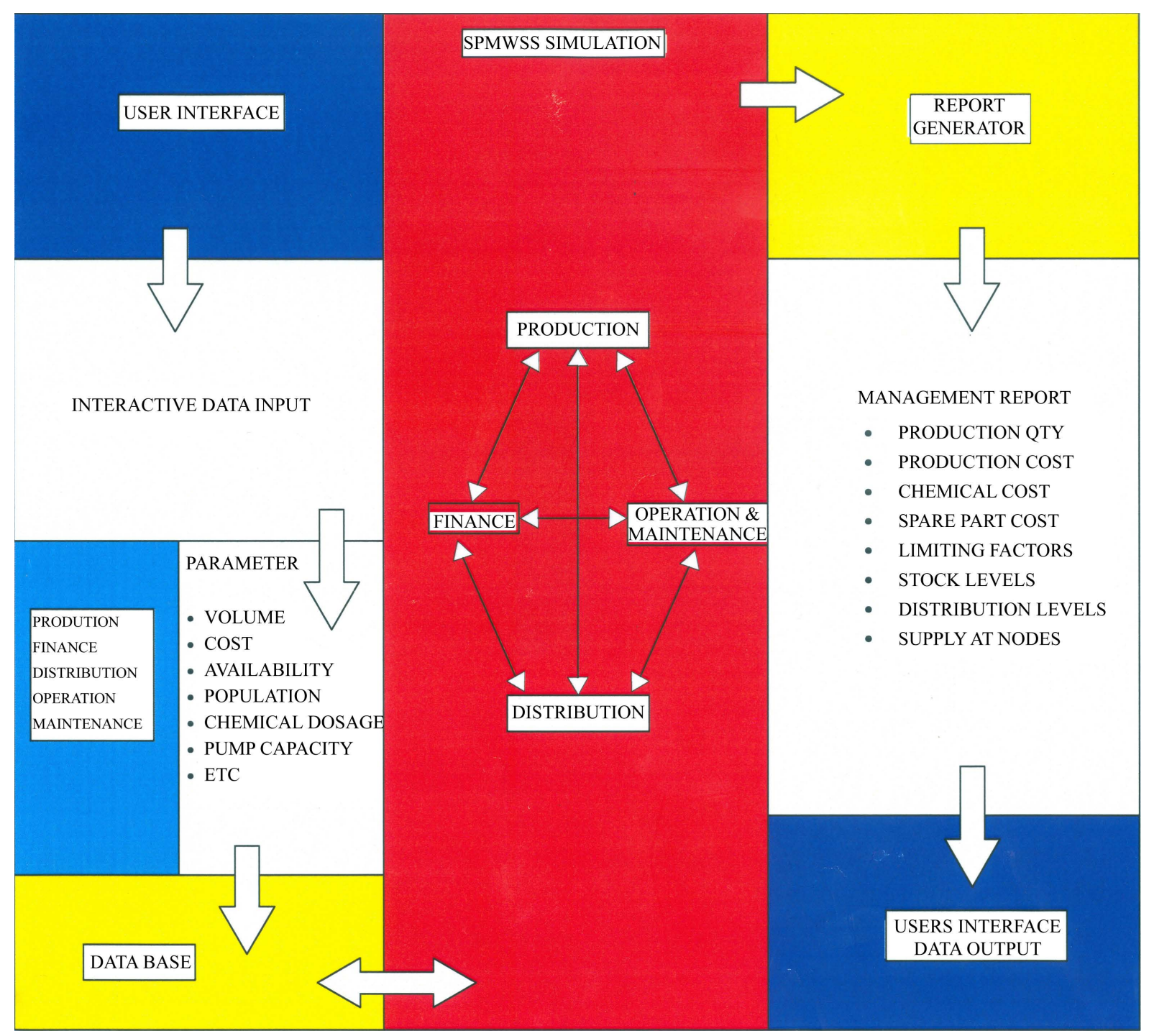

Figure 2. Concept of the SPMWSS model. Source: Adeniran (2007).

and the results presented.

Scenario 1: What if population should increase but per capita demand is constant?

Scenario 2: What if the plant efficiency should depreciate?

Scenario 3: What if there is a decline in raw water supply?

Scenario 4: What if the cost of energy (fuel and power) should increase?

Scenario 5: What if the plant efficiency should decrease?

Scenario 6: What if cost of raw water input from Eleyele intake (one of the raw water intake point), should increase?

Scenario 7: What if level of maintenance of the production plant should increase in order for production to remain constant?

Scenario 8: What if certain chemical dosage is applied, how much chemical?

Scenario 9: What if the production budget is required?

\section{Scenario 1: Population Increase but Constant per Capita Demand}

The simulation results of the above scenario are presented in Figure 5. The population is varied from 20,000 to 55,000 while the per capita water demand is kept at the WHO minimum of 110 litres. The cumulative annual productions are compared with the cumulative required production for each of the simulated situation. 


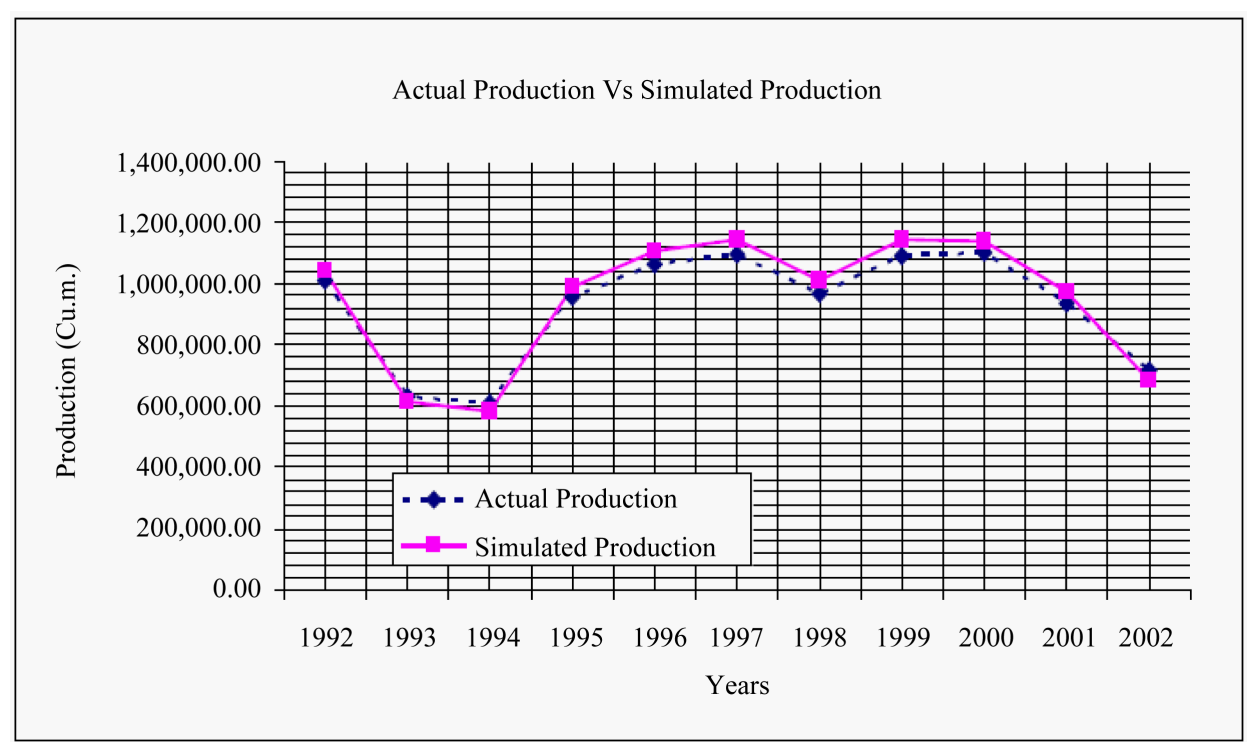

Figure 3. Chart of actual production vs. simulated production.

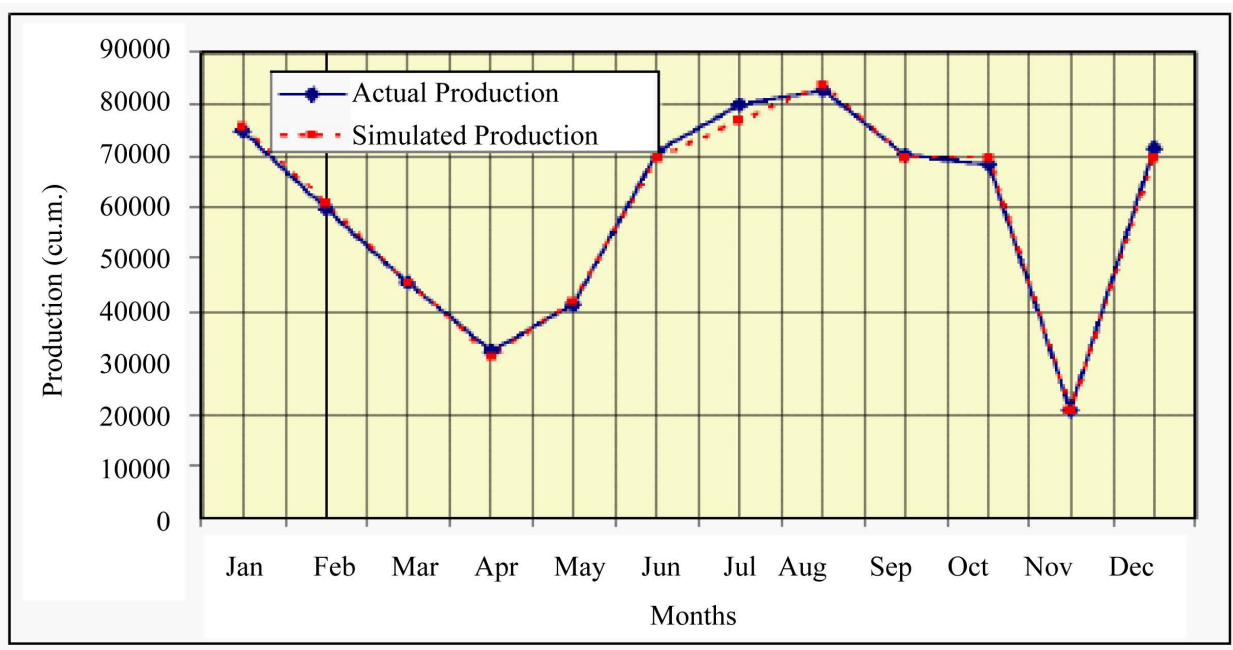

Figure 4. Year 2002 actual production vs. simulated production.

It is observed from Figure 5 that the Water Supply Scheme is capable of meeting the per capital demand of 110 litres per person per day up to a population of about 35,000 after which it can no longer cope.

\section{Scenario 2: Effect of Depreciating Plant Efficiency}

One of the major factors militating against the ability of a water supply scheme to meet with the demand of the consumers is equipment depreciation and/or lack of maintenance resulting in decrease in Plant Efficiency. The effect of plant efficiency on water production is examined vis-à-vis the demand for water by the population. For this case, the population and per capita demand are kept constant while the plant efficiency is varied. The observations are presented in graphical form as Figure 6.

It is observed from Figure 6 that the demanded quantity of water is the same as the quantity of water produced when the efficiency of the plant is higher than $65 \%$. In other words, the plant is capable of meeting the water demand of the population provided the efficiency is not below $70 \%$. However at lower efficiency, the plant would not be able to cope with the demanded water by the population. It should be noted that for this scenario investigation, the population and the per capita demand are kept constant.

The strategic planning implication of this is that regular maintenance activities should be carried out to ensure that the efficiency of any the components of the system does not drop below $70 \%$. This can be achieved by 


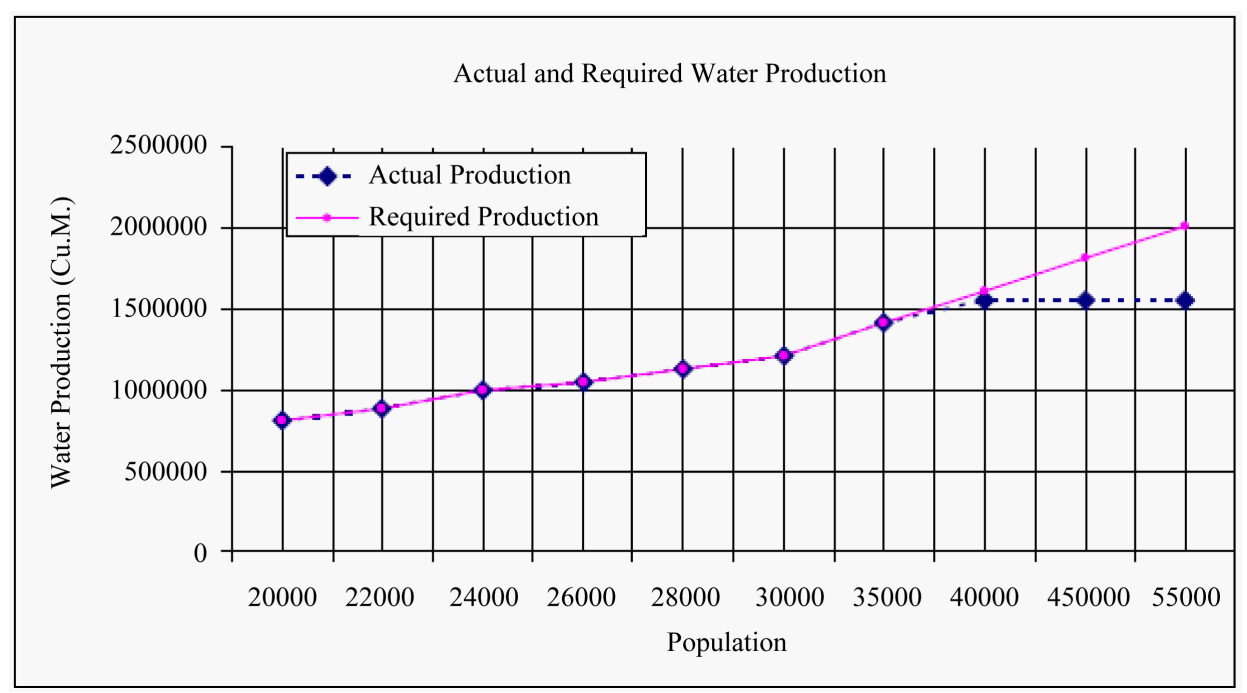

Figure 5. Actual production compared with water demand with varying population.

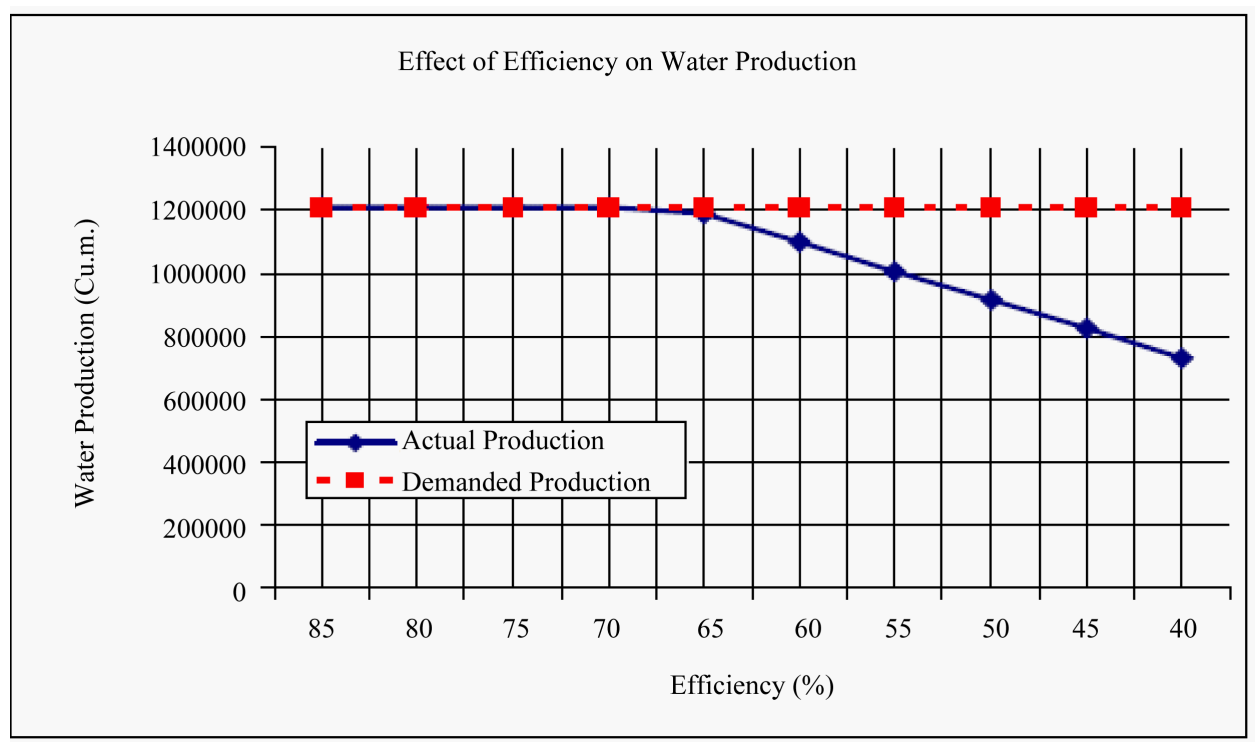

Figure 6. Effect of plant efficiency on water production.

conducting regular reliability tests on the equipment.

\section{Scenario 3: Declining Raw Water Supply}

At present, the UI Water supply system modeled obtains raw water from both Eleyele and Oba Dam. While Eleyele is an external supply source, the Oba Dam is an internal supply source. A situation that can arise is for Eleyele source may not be available or the Oyo State Government who is the owner of the dam could come up with an exclusion policy and the University is stopped from the abstraction of raw water from Eleyele Dam. Presently $60 \%$ of the University's raw water is from Eleyele. In order to simulate the above condition, the scenario in which the raw water input of Eleyele dam is reduced gradually from $60 \%$ to $0 \%$ is simulated. This is done by reducing the hours of operation of the Eleyele pumps form 20 hours a day to zero hours a day. For this scenario, the population is assumed to be 30000 and per capita demand is 110 litres. The effect of this scenario on water production is as shown in Figure 7.

From Figure 7, the limiting factor becomes 1.0 when the raw water contribution from Eleyele becomes $12.5 \%$. Any further reduction implies that the water demand of the population cannot be met. In fact, at $0 \%$ contribution from Eleyele, the limiting factor is 0.77. In other words, Oba Dam raw water source alone can cope 


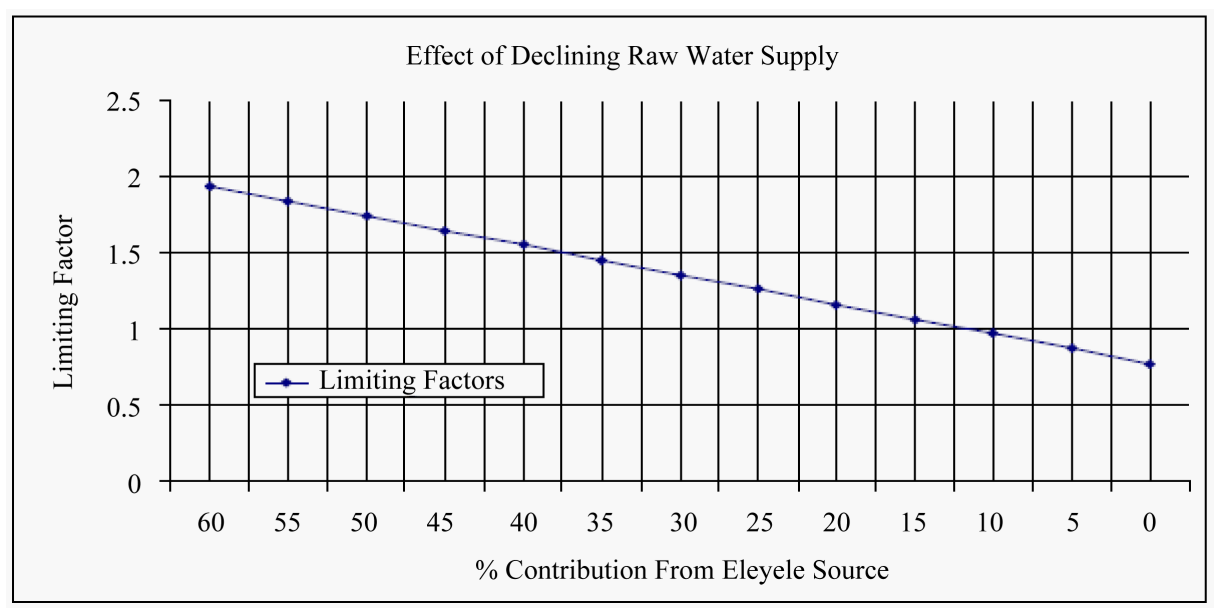

Figure 7. The effect of declining raw water supply on production.

with only $77 \%$ of the water demand of the population.

The strategic planning implication is for Management to plan ahead and look for alternative source of raw water. For instance, the long proposed Ona river dam (see Figure 8) could be a feasible option to counteract the effect of declining raw water supply either from Eleyele or Oba dam.

\section{Scenario 4: Increase in Cost of Fuel and Energy}

Some of the major costs of production include the cost of Fuel and Energy (PHCN). From 1992 to 2005, the Nigerian Economy witnessed many fluctuations in the cost of energy and fuels. The effects of these changes are examined using the model. First, the effect of changes in the cost of fuel alone is examined, then the effect of the cost of energy (PHCN) alone is examined, and then the combined effects of these changes are examined together. The simulation results of these effects on the cost of Production and the Unit cost of production are presented in the following sections.

\section{(a) Effect of Fuel Price on Unit Cost of Production}

Table 1 shows the effect of the various changes in the petroleum product prices between 1992 and 2005. It is seen that the unit cost of production rose from N55.68 to N97.17.

(b) The Effect of Cost of Energy on Unit Cost of Production

Table 2 shows the effect of the various changes in the unit cost of (PHCN) energy N/kWh between 1992 an 2005. It is seen that the unit cost of production rose from N59.12 to N85.48. This is a single factor simulation while the other factors are kept constant.

(c) The Combined Effect of Changes in Cost of Fuel and Energy

Usually, the changes in a factor lead to changes in other factors in real life. Especially, whenever there is a change in the cost of petroleum products there is usually a correspondence change in the cost of energy and vice versa. Figure 9 shows the changes.

It is seen that the cost of production increases with increases in cost of fuel and energy. This result is expected, but with the SPMWSS model, it is now possible to quantify the effect of any slight changes in any of these important factors. It should be noted that these results are for a fixed population and fixed production quantity. The model is also capable of examining the effect of the economy of scale with varying production quantities [1], [2].

\section{Scenario 5: Declining Plant Efficiency on Unit Cost of Production}

One of the major factors in cost consideration is the efficiency of the production plant. The reduction in the plant efficiency does not only affect the production output it also affect the cost of production. In order to observe the effects of the efficiency on the cost of production, the efficiency is gradually reduced from the normal operating efficiency of $85 \%$ to $5 \%$. The results of simulation are presented in the Figure 10.

It is seen from simulation results that the unit cost of production increases exponentially with linear declining of Plant Efficiency. It is obvious that it is not wise to operate the plant at low efficiency. The strategic plan implication of this is for adequate attention to be placed on maintenance such that efficiency is not allowed to drop. Any equipment that is operation below $70 \%$ efficiency should either be overhauled or replaced. 


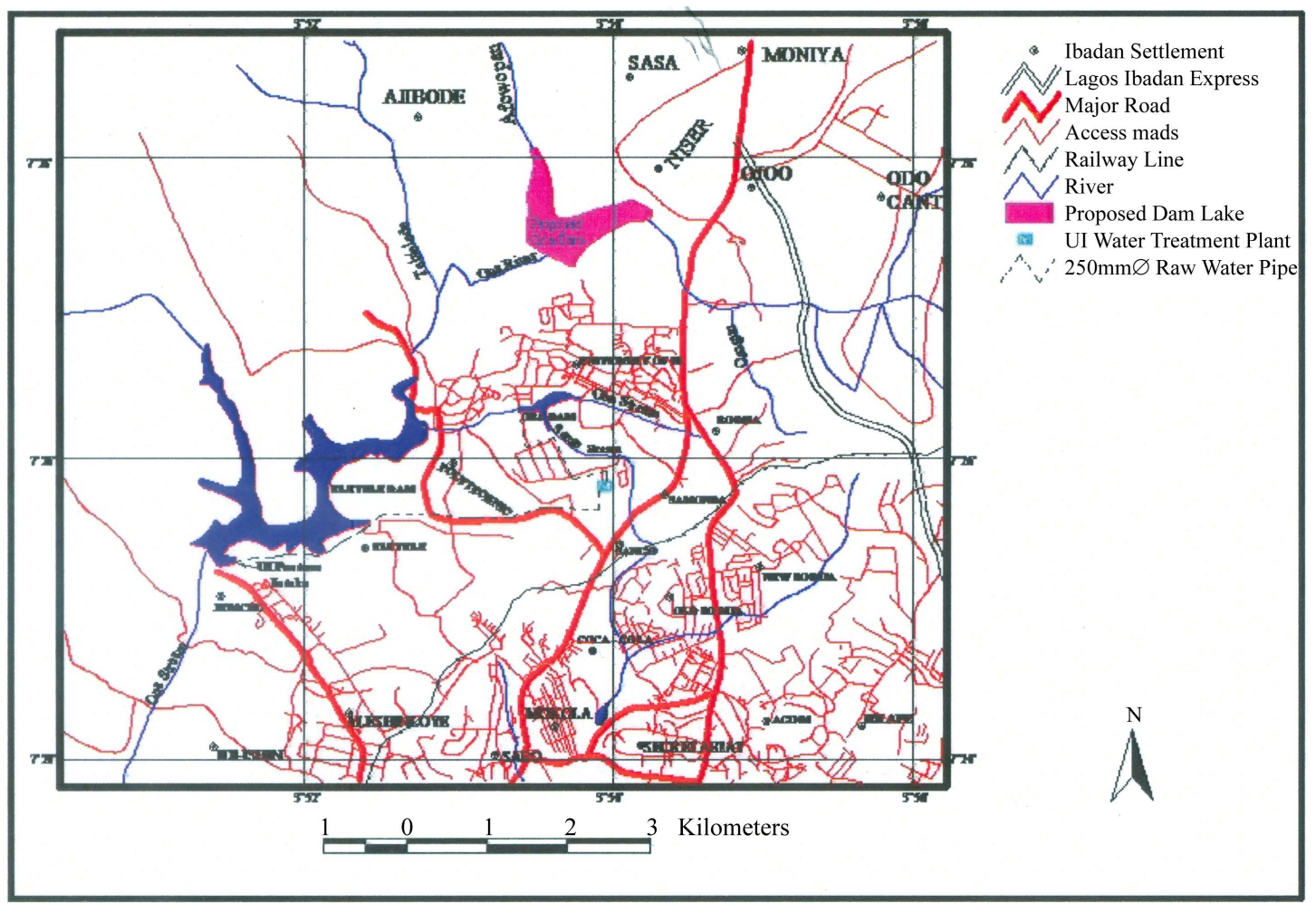

Figure 8. Map showing the locations of water supply reservoirs to university of Ibadan. Source: Works and Maintenance Department, University of Ibadan.

Table 1. The effect of changes in fuel prices on cost of production.

\begin{tabular}{rrrrrrrrrrr}
\hline PMS Price $=\mathbf{N}=$ & 0.70 & 3.23 & 11.00 & 25.00 & 20.00 & 22.00 & 26.00 & 34.00 & 49.90 & 50.50 \\
AGO Price $=\mathbf{N}=$ & 0.50 & 2.50 & 7.50 & 15.00 & 12.50 & 22.00 & 27.50 & 42.00 & 52.00 & 65.00 \\
Unit Cost $=\mathbf{N}=$ & 55.68 & 57.09 & 60.80 & 66.65 & 64.66 & 70.10 & 73.63 & 82.53 & 89.99 & 97.17 \\
\hline
\end{tabular}

Table 2. Effect of changes in unit cost of energy on unit cost of production.

\begin{tabular}{ccc}
\hline Year & Changing PHCN Price $=\mathbf{N}=/ \mathbf{k W h}$ & Corresponding Unit Cost $=\mathbf{N}=/ \mathbf{c u} . \mathbf{m}$ \\
\hline 1992 & 1.50 & 59.12 \\
1993 & 3.00 & 62.89 \\
1998 & 4.50 & 66.65 \\
1999 & 6.00 & 70.43 \\
2000 & 7.50 & 74.18 \\
2001 & 7.50 & 74.18 \\
2005 & 12.00 & 85.48 \\
\hline
\end{tabular}

\section{Scenario 6: Cost of Raw Water Input from Eleyele Intake}

Raw water is a major production input. At present, the University abstracts raw water from two sources, Eleyele Dam belonging to the Water Corporation of Oyo State (WCOS) and the Oba dam which belongs to the University. Payment of raw water to the WCOS has been very controversial from the inception of the University Scheme in 1990. The WCOS has insisted on payment for raw water and has increased the raw water tariff from N1.50, to N3.0 and now N6.0 per cu.m. In order to examine the effect of increase of raw water input from 


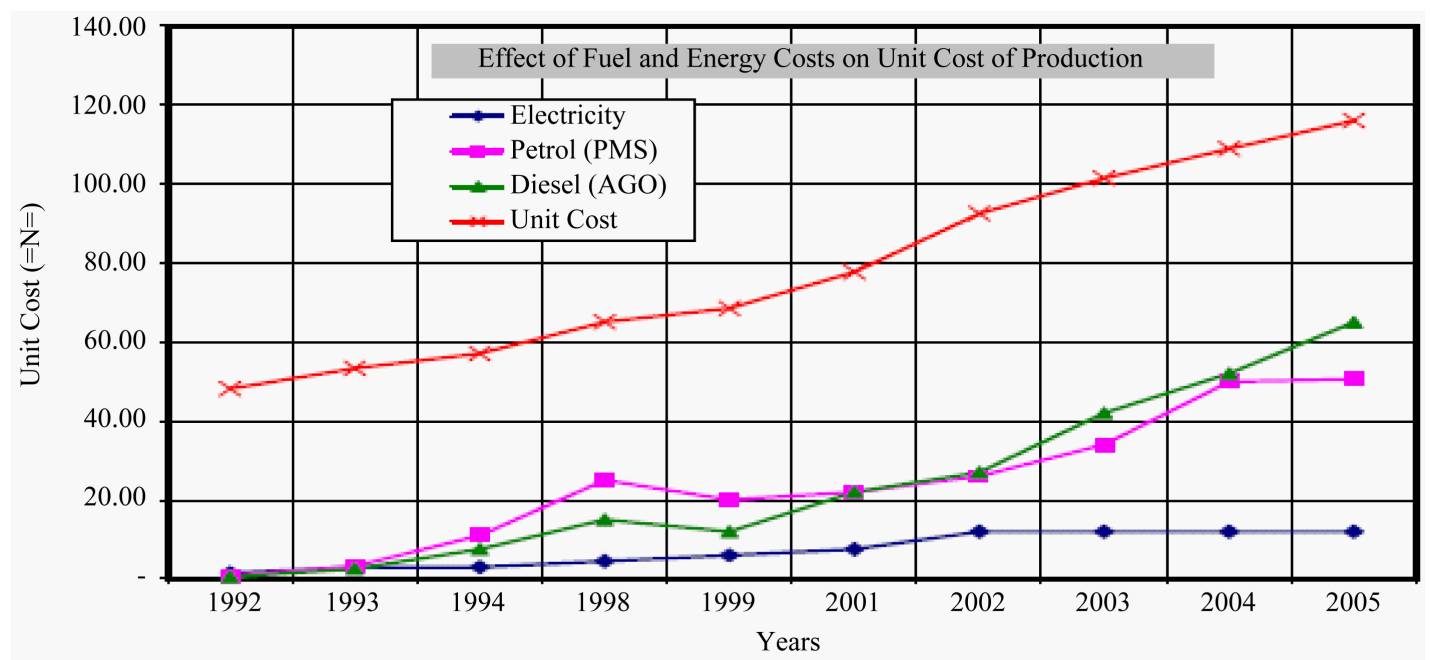

Figure 9. Effect of fuel and energy costs on unit cost of production.

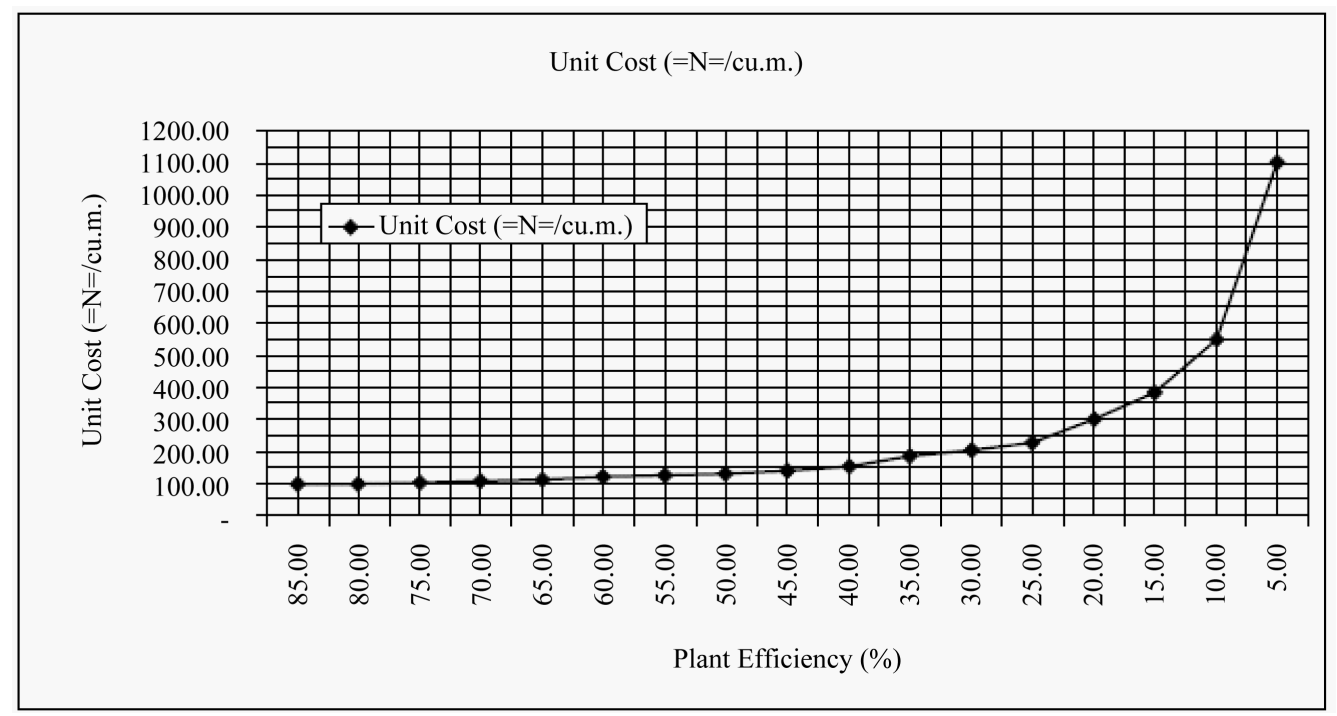

Figure 10. The effect of declining plant efficiency on unit cost of production.

Eleyele, a scenario is created in which the cost of raw water from Eleyele is increased from N3.0 to N100.00. The results are presented in Figure 11.

It is seen that the production cost increases as the cost of raw water input from Eleyele increases. The Strategic Planning implication is evident from this graphic example: Suppose the WCOS decides to increase the cost of raw water from the present N6.00 per cubic meter to say $=\mathrm{N}=100.00$ per cubic meter, the unit cost of production will change from $\mathrm{N} 92.11 / \mathrm{m}^{3}$ to $\mathrm{N} 234.53 / \mathrm{m}^{3}$. This type of information can be used as argument against an arbitrary increase in the cost of raw water. It can also be used to justify the need for the University to look for its own internal sources of raw water.

\section{Scenario 7: Increase in Level of Required Maintenance to Sustain Expected Production}

The plant capacity is usually fixed relative to the level of maintenance input. If the plant is to be expected to have a constant production level, then the maintenance activities on the plant must be kept regular. Managers and operators are often requested to keep the plant running without corresponding supply of spare parts to ensure the optimum performance of the plant. Effective and cost effective maintenance also involve keeping reasonable level of staff for the running of the plant as well as evolving control policies as to the level of fuel consumptions and running cost expenses. Strategic planning in the area of maintenance, therefore, places primary emphasis on cost control with respect to the level of maintenance for constant production output. 


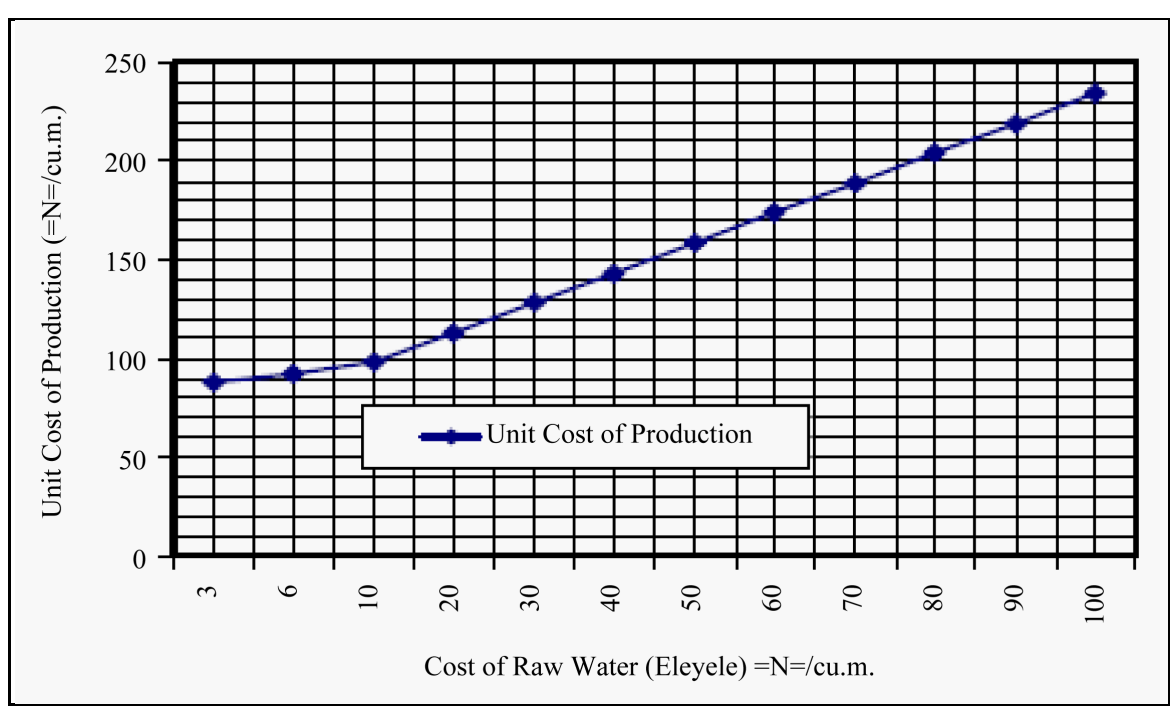

Figure 11. Effect of cost of raw water from Eleyele on unit cost of production.

The required level of maintenance of a system is a function of the maintenance input into the system. A new system requires a relatively low level of maintenance whereas a system that is tending towards unserviceability requires a very high level of maintenance. The aggregate of spare part usage, manpower attendance and down times are captured in terms of percentage. The required level of maintenance is varied from $10 \%$ to $100 \%$ while the production parameters are kept constant. The unit cost of production is observed for each of the simulated situation. The results are presented in Figure 12 and Table 3.

It is seen that the unit of production cost increases as the required level of maintenance increases. It is noted that when the level of maintenance is $0 \%$, the unit cost is $=\mathrm{N}=97.46$ whereas when the level of maintenance required rises up to $100 \%$ i.e. requiring shut down maintenance, the unit cost of production is $=\mathrm{N}=140.96$.

It is also noted from Table 3 that if the level of required maintenance should increase from $0 \%$ to only $10 \%$, the University has to look for an additional sum of $=\mathrm{N}=5,000,000.00$ in order to maintain production. The situation becomes worse with higher level of required maintenance. If the level of required maintenance is allowed to reach $100 \%$, the university must look for as much as $=\mathrm{N}=52,535,000.00$ for turnaround maintenance. The strategic planning implication is that management must evolve and sustain a maintenance policy that ensures routine maintenance in order to limit the production cost. Under no condition must equipment be allowed to depreciate to the level of breakdown maintenance.

\section{Scenario 8: Total Chemical Usage Given Chemical Dosage}

As an Expert System, the SPMWSS can be used as an oracle to tell the total quantities of chemical expected to be used if the level of chemical dosages at each period of the planning horizon is known. The model can thus be used to monitor chemical usage of the treatment plant and thus prevent and or detect theft. In this example, Alum alone is used. However, other chemicals can be equally monitored. The dosage of Alum is varied from 80 $\mathrm{ppm}$ to $180 \mathrm{ppm}$ based on the turbidity profile of the raw water which varies from season to season. The best Alum dosage is about $80 \mathrm{ppm}$ while the worse is about $180 \mathrm{ppm}$ at the peak of the raining season. Table 4 shows the expected Total Annual Alum usage at a given dosage. This information can be used to intelligently figure out the quantity of Alum that Management should purchase if the average dosage in a year is known.

\section{Scenario 9: Expert System for Production Budget}

One of the attributes of the SPMWSS model is its budgeting capability. In a public establishment, budgets are often required within a short time frame. Such budgets are usually prepared using the rule of the thumb. SPMWSS model is an Expert System for preparing production budget because all the financial components for preparing a production budget have been built into the model. In actual sense, the total cost under certain conditions can be given as a model output as shown in Table 5. It is seen from this table that cumulative costs of each of the vital production item for the simulated condition are presented. Thus it is known that about $=\mathrm{N}=$ $6,161,200$ is required for Chemicals while about $=\mathrm{N}=511,000.00$ is required for spare parts and a total of $=\mathrm{N}=$ $117,716,000$ is the total money required for the water sector during the planning year. 


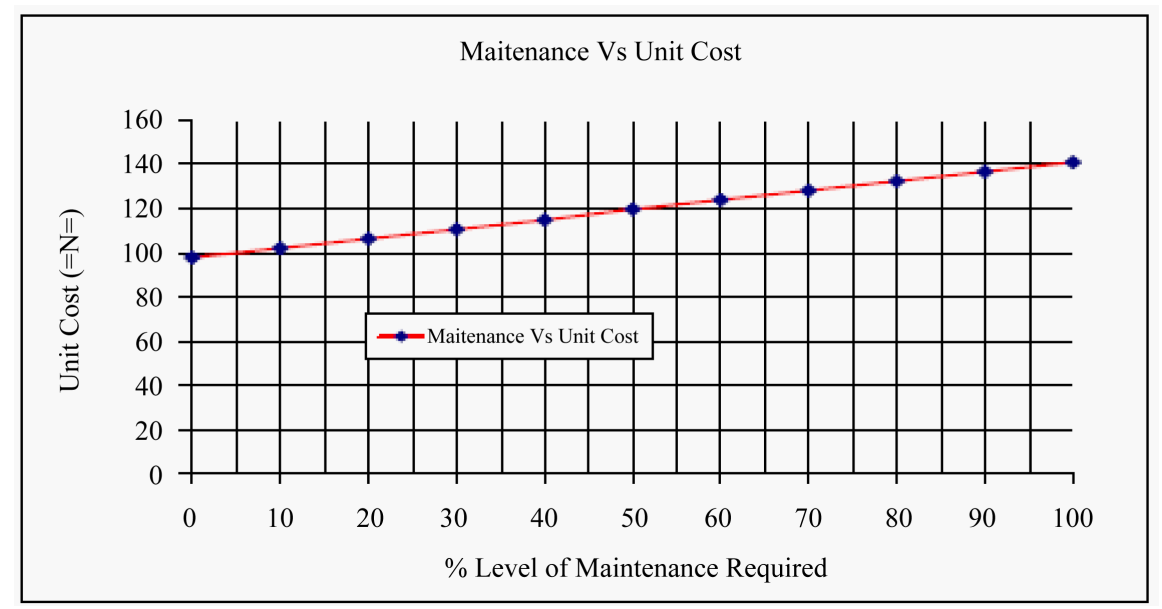

Figure 12. Effect of increased level of maintenance on unit cost of production.

Table 3. Effect of increased level of maintenance on cost of production.

\begin{tabular}{ccc}
\hline \% Level of Required Maintenance & Total Production Cost $=\mathrm{N}=: \mathrm{k}$ & Unit Cost of Production $=\mathrm{N}=: \mathrm{k}$ \\
\hline 0 & $117,716,000.00$ & 97.46 \\
10 & $122,977,000.00$ & 101.82 \\
20 & $128,218,000.00$ & 110.16 \\
30 & $133,468,000.00$ & 114.85 \\
40 & $138,711,000.00$ & 119.21 \\
50 & $143,976,000.00$ & 123.57 \\
60 & $149,242,000.00$ & 127.91 \\
70 & $154,486,000.00$ & 132.25 \\
90 & $159,727,000.00$ & 136.59 \\
\hline
\end{tabular}

Table 4. Total alum usage given dosage level.

\begin{tabular}{cccccccccccc}
\hline $\begin{array}{c}\text { Alum Dosage } \\
\text { (ppm) }\end{array}$ & 80 & 90 & 100 & 110 & 120 & 130 & 140 & 150 & 160 & 170 & 180 \\
Alum Usage (Kg) & 96,627 & 108,702 & 120,780 & 132,840 & 144,960 & 157,020 & 169,080 & 181,121 & 193,260 & 205,320 & 217,380 \\
\hline
\end{tabular}

\section{Conclusion}

In this paper, the development of a computer based strategic planning model for a water supply scheme has been reported. The model is developed using the DYNAMO modeling software. However, in order to create a userfriendly environment, other application programs such as FORTRAN, CLIPPER 5 DBASE, EXCEL and EPIGLUE have also been used in an integrated manner. The model was validated using existing data that spanned ten (10) years from the University of Ibadan Water Supply Scheme. The model was then used to carry out scenario experimentations for strategic planning. The results presented indicate that an SPMWSS model has been successfully developed to handle the operation of the University of Ibadan Water Supply Scheme. The potential of greater understanding of a system through the system dynamics approach, which is still in its infancy, is shown to be not only feasible but also exciting. The model is found useful to managers and planners for its strategic planning capability. The SPMWSS model integrates the production and financial elements; in addition to 
Table 5. Cumulative costs of various production item.

\begin{tabular}{|c|c|c|c|c|c|c|c|}
\hline PERIOD & TOTAL EXP. & CHEN. COST & SPARE PARTS & INCIDENTALS & SALARY & POWER COST & TRANSPORT \\
\hline $\mathrm{N}$ & $\mathrm{N}$ & $\mathrm{N}$ & $\mathrm{N}$ & $\mathrm{N}$ & $\mathrm{N}$ & $\mathrm{A}$ & $\mathrm{N}$ \\
\hline 1 & $9,723,000.00$ & $454,400.00$ & 5000.00 & 5000.00 & $940,000.00$ & $3,081,000.00$ & $4,067,000.00$ \\
\hline 2 & $18,901,000.00$ & $879,500.00$ & $16,000.00$ & $10,000.00$ & $1,880,000.00$ & $5,963,000.00$ & $7,872,000.00$ \\
\hline 3 & $28,645,000.00$ & $1,333,900.00$ & $42,000.00$ & $15,000.00$ & $2,820,000.00$ & $9,044,000.00$ & $11,939,000.00$ \\
\hline 4 & $38,120,000.00$ & $1,773,800.00$ & $74,000.00$ & $20,000.00$ & $3,760,000.00$ & $12,026,000.00$ & $1,587,500.00$ \\
\hline 5 & $47,879,000.00$ & $2,264,000.00$ & $79,000.00$ & $25,000.00$ & $4,700,000.00$ & $15,107,000.00$ & $19,942,000.00$ \\
\hline 6 & $57,396,000.00$ & $2,773,200.00$ & $84,000.00$ & $30,000.00$ & $5,640,000.00$ & $18,089,000.00$ & $23,878,000.00$ \\
\hline 7 & $68,156,000.00$ & $3,370,800.00$ & $260,000.00$ & $35,000.00$ & $6,730,000.00$ & $21,125,000.00$ & $28,559,000.00$ \\
\hline 8 & $7,891,600.00$ & $3,968,400.00$ & $436,000.00$ & $40,000.00$ & 7,820,000.00 & $24,161,000.00$ & $33,240,000.00$ \\
\hline 9 & $88,497,000.00$ & $4,546,900.00$ & $436,000.00$ & $45,000.00$ & $8,760,000.00$ & $27,143,000.00$ & $37,176,000.00$ \\
\hline 10 & $98,370,000.00$ & $5,144,500.00$ & $448,000.00$ & $50,000.00$ & $9,700,000.00$ & $30,224,000.00$ & $41,243,000.00$ \\
\hline 11 & $107,930,000.00$ & $5,671,000.00$ & $479,000.00$ & $55,000.00$ & $10,640,000.00$ & $33,206,000.00$ & $45,179,000.00$ \\
\hline 12 & $117,116,000.00$ & $6,161,200.00$ & $511,000.00$ & $60,000.00$ & $11,580,000.00$ & $36,287,000.00$ & $49,246,000.00$ \\
\hline
\end{tabular}

achieving true total cost perspective, this particular capability introduces the potential flow paths from production to consumption. The SPMWSS provides a mechanism wherein the modeled system can be examined under scenario experiments. In addition, many other aspects of system management as they relate to water supply can be tested in an effort to evaluate existing policies and principles.

\section{References}

[1] Adeniran, A.E. and Bamiro, O.A. (2010) A System Dynamics Strategic Planning Model for a Municipal Water Supply Scheme. Proceedings of the International Conference of the System Dynamics Society, Seoul, 25-29 July 2010.

[2] Adeniran, A.E. (2014) Application of System Dynamics Model in the Determination of the Unit Cost of Production of Drinking Water. International Journal of Water Resources and Environmental Engineering, 6, 183-192. http://dx.doi.org/10.5897/IJWREE2013.0479

[3] Adeniran, A.E. (2007) Development of a System Dynamics Strategic Planning Model for a Municipal Water Supply System. Ph.D. Thesis, University of Ibadan, Ibadan.

[4] World Bank (1993) A Strategy for Managing Water in the Middle East and North Africa, IBRD. World Bank, New York.

[5] Forester, J.W. (1961) Industrial Dynamics. MIT Press, Cambridge.

[6] Forrester, J.W. (1992) Policies, Decisions and Information Sources for Modeling. European Journal of Operation Research, 59, 42-63. http://dx.doi.org/10.1016/0377-2217(92)90006-U

[7] Fletcher, E.J. (1998) The Use of System Dynamics as a Decision Support Tool for the Management of Surface Water Resources. First International Conference on New Information Technologies for Decision Making in Civil Engineering, Montreal, 11-13 October 1998, 909-920.

[8] Ford, A. (1999) Modeling the Environment-An Introduction to System Dynamics Modeling of Environmental Systems. Island Press, Washington DC.

[9] Deaton, M.L. and Winebrake, J.I. (1999) Dynamic Modeling of Environmental Systems. Springer-Verlag, New York.

[10] Huang, G.H. and Chang, N.B. (2003) Perspectives of Environmental Informatics and Systems Analysis. Journal of Environmental Informatics, 1, 1-6. http://dx.doi.org/10.3808/jei.200300001

[11] Bamiro, A.O. (1995) Electronic Oracle-Seeing through Computer Models. Post Graduate School Interdisciplinary Discourse, University of Ibadan, Ibadan. 